\title{
SISTEM REKOMENDASI PEMILIHAN DOSEN PEMBIMBING SKRIPSI MENGGUNAKAN METODE WEIGHTED PRODUCT ( STUDI KASUS STIMIK DHARMA WACANA METRO)
}

\author{
${ }^{1}$ Wilda Yulianti ${ }^{2}$ Budi Sutomo ${ }^{3}$ Andreas Perdana \\ Program Studi Teknik Informatika, STIMIK Dharma Wacana Metro \\ Dosen Tetap Teknik Informatika STIMIK Dharma Wacana Metro \\ Jalan Kenanga No. Mulyojati Kota Metro \\ E-Mail : Wildayulianti5@gmail.com
}

\begin{abstract}
ABSTRAK
Perguruan tinggi Dharma Wacana Metro merupakan perguruan tinggi dibawah naungan yayasan pendidikan, yang memiliki 4 (empat) perguruan tinggi salah satunya STIMIK Dharma Wacana Metro yang mempunyai program studi bidang komputer (Sistem Informasi dan Teknik Informatika). Dalam menyelesaikan skripsi mahasiswa perlu mempunyai pembimbing skripsi yang membantu proses penyusunan skripsi, dalam pemilihan dosen pembimbing skripsi proses yang dilakukan ketua jurusan untuk memilih dosen sebagai membimbing melihat berdasarkan kreteria riwayat mengajar, riwayat pendidikan terkhir, bidang keahlian, jabatan fungsional. Weighted product adalah suatu metode yang digunakan untuk menyelesaikan suatu proses perhitungan berdasarkan kreteria riwayat mengajar, riwayat pendidikan terkhir, bidang keahlian, jabatan fungsional yang nantinya untuk mendapatkan suatu rekomendasi pembimbing skripsi. kemudian nantinya akan dijadikan suatu sistem rekomendasi pemilihan dosen pembimbing skripsi menggunakan metode weighted product.
\end{abstract}

Kata Kunci : Sistem Rekomendasi, Pemilihan Dosen, Pembimbing Skripsi, Weighted Product

\section{PENDAHULUAN}

Perguruan Tinggi Dharma Wacana Metro Merupakan Perguruan Tinggi dibawah naungan Yayasan Pendidikan yang beralamat di Jl. Kenangan No.03 Mulyojati Metro Barat, Kota Metro, Lampung 34111. Yayasan Pendidikan Dan Kebudayaan Dharma Wacana Metro memiliki 4 Perguruan Tinggi, salah satunya STMIK Dharma Wacana Metro. STMIK Dharma Wacana Metro mempunyai Program Studi bidang Komputer (S1 Sistem Informasi dan S1 Teknik Informatika). (STMIK, 2017)

Dalam menyelesaikan skripsi mahasiswa perlu memiliki pembimbing skripsi yang membantu proses penyusunan skripsi, dalam pemilihan dosen pembimbing skripsi tahapan yang dilakukan ketua jurusan untuk memilih dosen sebagai membimbing melihat berdasarkan kreteria riwayat mengajar, riwayat pendidikan terkhir, bidang keahlian, jabatan fungsional.

Rekomendasi adalah sesuatu yang bersifat menganjurkan atau membenarkan seseorang. Metode yang digunakan dalam memberikan rekomendasi Weighted product adalah metode yang digunakan untuk menyelesaikan suatu proses perhitungan berdasarkan kriteria riwayat mengajar, riwayat pendidikan terkhir, bidang keahlian, jabatan fungsional yang nantinya untuk mendapatkan rekomendasi pembimbing skripsi. Kemudian nantinya akan dijadikan sistem rekomendasi pemilihan dosen 
pembimbing skripsi menggunakan metode weighted product.

2. Metode Weighted Product (WP)

weighted product merupakan metode yang menggunakan perhitungan perkalian untuk menghubungkan rating atribut, dimana rating setiap atribut harus dipangkatkan terlebih dulu dengan bobot yang berkaitan. Rumus untuk alternatif $\mathrm{Si}$ diberikan sebagai berikut (Kusumadewi, 2006):

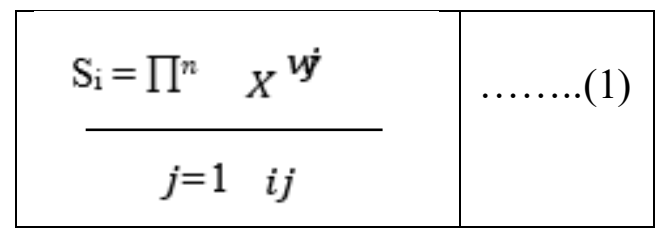

dengan $i=1,2, \ldots, m$. dimana:

$\mathrm{S} \quad$ :Preferensi alternatif dianologikan sebagai vektor

S X : Nilai kriteria

W : Bobot kriteria/subkriteria

I : Alternatif

J : Kriteria

$\mathrm{N} \quad$ : Banyaknya kriteria

Rumus :

$$
V_{1}=\frac{\Pi_{j=1}^{n} X^{i j} w j}{\Pi_{j=1}^{n}\left(X^{i} j\right) \dot{y}}
$$

\section{HASIL DAN PEMBAHASAN}

\section{a. Tahap dalam menggunakan} metode weighted product.

1. Menentukan tingkat prioritas bobot setiap kreteria

2. Menghitung bobot kriteria ( $\mathrm{Wj}$ )

3. Melakukan perhitungan vektor S

4. Melakukan perhitungan vektor $\mathrm{V}$ dengan cara (hasil perhitungan masing-masing vektor $\mathrm{Si}$ dibagi dengan jumlah hasil perhitungan seluruh vektor $S$ ).

5. Dari hasil perhitungan vektor $\mathrm{V}$ sebagai dasar pengambilan keputusan. Nilai V terbesar merupakan pilihan alternatif yang terbaik

Contoh kasus :

Ada seorang Mahasiswa TI mengambil mata kuliah skripsi untuk menyelesaikan tugas skripsinya, dengan judul yang dia miliki, mahasiswa perlu dosen pembimbing yang sesuai dengan judul yang telah ada contohnya judul "Sistem Pakar Fuzzy Untuk Diagnosis penyakit kudis

Menggunakan Metode Mamdani" judul tersebut masuk kedalam kategori bidang keahlian artificial intellegence, untuk mengetahui dosen siapa saja yang mampu di bidang keahlian tersebut berdasrkan judul yang ada maka kita gunakan metode weighted product (WP) dalam penyelesaikan kasus ini, adapun data dosen yang sesuai dengan kasus diatas adalah sebagai berikut.

\section{Tabel data Dosen}

Berikut adalah contoh dari perhitungan model weighted product. Dari masingmasing kriteria tersebut akan ditentukan bobot-bobotnya yaitu:

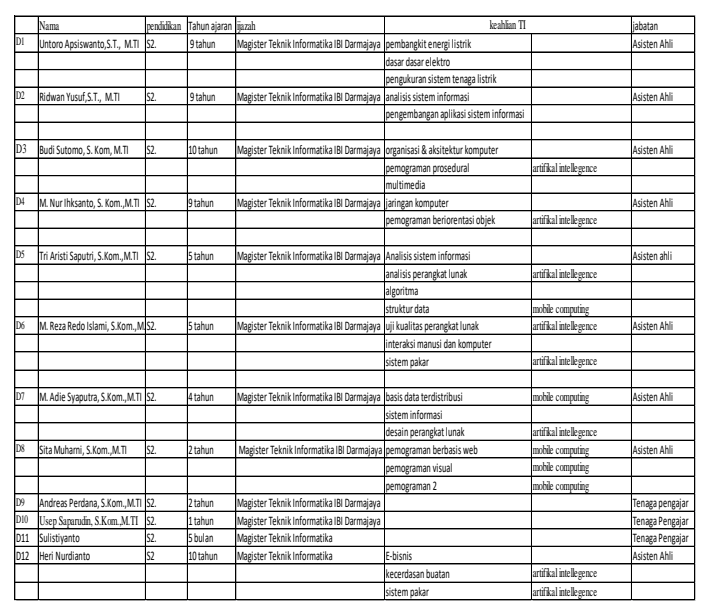

Tidak memenuhi syarat $=1$

Kurang memenuhi syarat $=2$

Cukup memenuhi syarat $=3$

Memenuhi syarat $\quad=4$

Sangat memenuhi syarat $=5$

a. Penjelasan Terhadap Pembobotan 
Dalam metode weighted product untuk sistem penunjang keputusan penentuan pembimbing tugas akhir ini ada beberapa kriteria, yaitu:

\section{Keahlian}

Keahlian adalah kemampuan yang dimiliki seseorang, contoh di bawah ini penilaian dari bidang keahlian dilihat dari seberpa banyak mata kuliah dalam 1 bidang yang iya ajarkan atau pernah di ajarkan, Berikut ini tabel 1.1 kriteria keahlian.

Tabel 1.1 Kriteria Keahlian

\begin{tabular}{|c|c|c|}
\hline \multicolumn{3}{|c|}{ KEAHLIAN } \\
\hline kreteria Keahlian & bobot & keterangan \\
\hline ijazah dan keahlian sesuai & 5 & sangat memenuhi syarat \\
\hline ijazah sesuai dan keahlian tidak sesuai & 4 & memenuhi syarat \\
\hline jagzah sesuai \& keahlian tidak ada & 3 & cukup memenuhi syarat \\
\hline jjazah tidak sesuai \& keahlian tidak ada & 2 & kurang memenuhi syarat \\
\hline jiazah \& keahlian tidak ada & 1 & Tidak memenuhi syarat \\
\hline
\end{tabular}

\section{Jabatan Fungsoinal}

Jabatan fungsional merupakan kedudukan yang menunjukkan tugas, tanggung jawab, wewenang dan hak seorang dosen. Pembagian jabatan fungsional dapat dilihat pada tabel 1.2

Tabel 1.2 Jabatan

\section{Fungsional}

\begin{tabular}{|c|c|c|}
\hline \multicolumn{3}{|c|}{ JABATAN FENGSSONAL } \\
\hline ketetria & bobot & keterangan \\
\hline Profesor & 5 & sangat memenuhi syarat \\
\hline Eltororkenda & 4 & memenuhi syarat \\
\hline |eltor & 3 & cakup memenuhhisyarat \\
\hline asisten ahli & 2 & kurang memenuhi syarat \\
\hline tenaga mengajar & 1 & tidak memenduhis syarat \\
\hline
\end{tabular}

\section{Riwayat mengajar}

Riwayat mengajar merupakan mata kuliah yang pernah diajarkan dan merupakan suatu keahlian dosen berikut tabel riwayat mengajar dosen 1.3
Tabel riwayat mengajar 1.3

\begin{tabular}{|l|c|l|}
\hline \multicolumn{4}{|c|}{ RIWAYATMEVGAJAR } \\
\hline kreteria & bobot & keterangan \\
\hline mengajar $\geq 9$ tahun & 5 & sangat memenuhisyarat \\
\hline mengajar $\geq 7$ tahun & 4 & memenuhi syarat \\
\hline mengajar $\geq 5$ tahun & 3 & cukup memenuhi syarat \\
\hline mengajar $\geq 2$ tahun & 2 & kurang memenuhi syarat \\
\hline mengajar $\leq 1$ tahun & 1 & tidak memenuhi syarat \\
\hline
\end{tabular}

\section{Pendidikan}

Pendidikan adalah suatu riwayat pembelajaran dari seseorang berikut adalah tabel riwayat pendidikan tabel 1.4

Tabel 1.4 Pendidikan

\begin{tabular}{|l|c|l|}
\hline \multicolumn{3}{|c|}{ PENDIDKAN } \\
\hline Kreteria & bobot & keterangan \\
\hline S3 & 5 & sangat memenuhi syarat \\
\hline$S 2$ & 4 & memenuhi syarat \\
\hline
\end{tabular}

\section{a. Tahap selanjutnya} Penentuan Bobot Awal (W)

Penentuan bobot awal adalah menentukan diantara kriteria yang telah disebutkan sebelumnya, manakah kriteria yang memiliki nilai kepentingan tertinggi.

Tabel 1.5 Kreteria pembobotan awal atau prioritas

\begin{tabular}{|l|c|}
\hline Kreteria & Bobot \\
\hline pendidikan & 35 \\
\hline jabatan & 30 \\
\hline riwayat & 20 \\
\hline keahlian & 15 \\
\hline Jumlah & 100 \\
\hline
\end{tabular}

b. Penentuan alternatif dan memberi nilai untuk tiap kriteria pada alternative

Berikut adalah nilai kriteria untuk masing-masing alternatif untuk bidang judul tugas akhir Jaringan.

1. Menentukan semua nilai kriteria untuk masingmasing alternatif dan bobot awal dari setiap kriteria bisa dilihat pada table dibawah ini.

Tabel 1.6 Penilaian kreteria 
dari tiap alternative

\begin{tabular}{|c|c|c|}
\hline Alternatif 1 & Kreteria & Bobot \\
\hline \multirow[t]{4}{*}{ Untoro Apsiswanto,S.T., M.TI } & pendidikan & 4 \\
\hline & jabatan & 2 \\
\hline & Riwayat mengajar & 5 \\
\hline & Bidang keahlian & 4 \\
\hline Alternatif 2 & Kreteria & Bobot \\
\hline \multirow[t]{4}{*}{ M. Reza Redo Islami, S.Kom.,M.TI } & pendidikan & 4 \\
\hline & jabatan & 2 \\
\hline & Riwayat mengajar & 3 \\
\hline & Bidang keahlian & 5 \\
\hline Alternatif 3 & Kreteria & Bobot \\
\hline \multirow[t]{4}{*}{ Sita Muharni, S.Kom.,M.TI } & pendidikan & 4 \\
\hline & jabatan & 2 \\
\hline & Riwayat mengajar & 2 \\
\hline & Bidang keahlian & 4 \\
\hline Alternatif 4 & Kreteria & Bobot \\
\hline \multirow[t]{4}{*}{ Ridwan Yusuf,S.T., M.TI } & pendidikan & 4 \\
\hline & jabatan & 2 \\
\hline & Riwayat mengajar & 5 \\
\hline & Bidang keahlian & 4 \\
\hline Alternatif 5 & Kreteria & Bobot \\
\hline \multirow[t]{4}{*}{ Budi Sutomo, S. Kom, M.TI } & pendidikan & 4 \\
\hline & jabatan & 2 \\
\hline & Riwayat mengajar & 5 \\
\hline & Bidang keahlian & 5 \\
\hline Alternatif 6 & Kreteria & Bobot \\
\hline \multirow{4}{*}{ M. Nur Ihksanto, S. Kom.,M.TI } & pendidikan & 4 \\
\hline & jabatan & 2 \\
\hline & Riwayat mengajar & 5 \\
\hline & Bidang keahlian & 5 \\
\hline Alternatif 7 & Kreteria & Bobot \\
\hline \multirow{4}{*}{ Tri Aristi Saputri, S.Kom.,M.TI } & pendidikan & 4 \\
\hline & jabatan & 2 \\
\hline & Riwayat mengajar & 3 \\
\hline & Bidang keahlian & 5 \\
\hline Alternatif 8 & Kreteria & Bobot \\
\hline \multirow[t]{4}{*}{ M. Adie Syaputra, S.Kom.,M.TI } & pendidikan & 4 \\
\hline & jabatan & 2 \\
\hline & Riwayat mengajar & 2 \\
\hline & Bidang keahlian & 5 \\
\hline Alternatif 9 & Kreteria & Bobot \\
\hline \multirow{4}{*}{ Andreas Perdana, S.Kom.,M.TI } & pendidikan & 4 \\
\hline & jabatan & 1 \\
\hline & Riwayat mengajar & 2 \\
\hline & Bidang keahlian & 3 \\
\hline Alternatif 10 & Kreteria & Bobot \\
\hline \multirow[t]{4}{*}{ Usep Saparudin, S.Kom.,M.TI } & pendidikan & 4 \\
\hline & jabatan & 1 \\
\hline & Riwayat mengajar & 1 \\
\hline & Bidang keahlian & 3 \\
\hline Alternatif 11 & Kreteria & Bobot \\
\hline \multirow[t]{4}{*}{ Sulistiyanto, S.Kom.,M.TI } & pendidikan & 4 \\
\hline & jabatan & 1 \\
\hline & Riwayat mengajar & 1 \\
\hline & Bidang keahlian & 3 \\
\hline Alternatif 12 & Kreteria & Bobot \\
\hline \multirow[t]{4}{*}{ Heri Nurdianto, S.Kom.,M.TI } & pendidikan & 4 \\
\hline & jabatan & 2 \\
\hline & Riwayat mengajar & 5 \\
\hline & Bidang keahlian & 5 \\
\hline
\end{tabular}

2. Kemudian memnerbaiki bobot dengan cara $\quad W_{1}=\frac{v v}{\Sigma w}$

dimana pada tahapan ini kita menghitung perbaikan bobot awal, yaitu dari kreteria keahlian di bagi dengan jumlah keseluruhan bobot yang ada pada tabel bobot awal, adapun contoh dari perhitungannya dapat di lihat pada tabel di bawah ini.

Tabel 1.7 perbaikan bobot

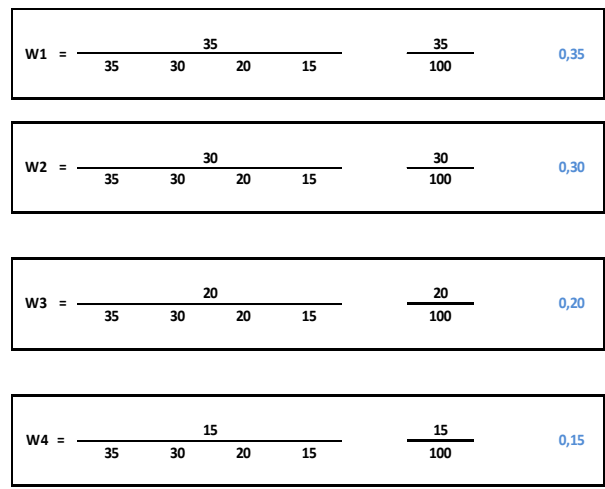

3. Kemudian menghitung nilai / skor untuk alternative nilai setiap alternatif di pangkatkan dengan hasil perbaikan bobot dapat di hitung dengan cara berikut:

\section{Tabel 1.8 Perhitungan Nilai $S$}

\section{$S 1=\quad\left(4^{\wedge} 0,35\right)^{*}\left(2^{\wedge} 0,3\right)^{*}\left(5^{\wedge} 0,2\right)^{*}\left(4^{\wedge} 0,15\right)=3,39$}

$S 2=\quad\left(4^{\wedge} 0,35\right)^{*}\left(2^{\wedge} 0,3\right)^{*}\left(3^{\wedge} 0,2\right)^{*}\left(5^{\wedge} 0,15\right)=3,17$

$53=\quad\left(4^{\wedge} 0,35\right)^{*}\left(2^{\wedge} 0,3\right)^{*}\left(2^{\wedge} 0,2\right)^{*}\left(4^{\wedge} 0,15\right)=2,82$

$54=\quad\left(4^{\wedge} 0,35\right)^{*}\left(2^{\wedge} 0,3\right)^{*}\left(5^{\wedge} 0,2\right)^{*}\left(4^{\wedge} 0,15\right)=3,39$

$55=\quad\left(4^{\wedge} 0,35\right)^{*}\left(2^{\wedge} 0,3\right)^{*}\left(5^{\wedge} 0,2\right)^{*}\left(5^{\wedge} 0,15\right)=3,51$

$S 6=\quad\left(4^{\wedge} 0,35\right)^{*}\left(2^{\wedge} 0,3\right)^{*}\left(5^{\wedge} 0,2\right)^{*}\left(5^{\wedge} 0,15\right)=3,51$

$57=\quad\left(4^{\wedge} 0,35\right)^{*}\left(2^{\wedge} 0,3\right)^{*}\left(3^{\wedge} 0,2\right)^{*}\left(5^{\wedge} 0,15\right)=3,17$

$58=\quad\left(\left(4^{\wedge} 0,35\right)^{*}\left(2^{\wedge} 0,3\right)^{*}\left(2^{\wedge} 0,2\right)^{*}\left(5^{\wedge} 0,15\right)=2,92\right.$

$s 9=\quad\left(4^{\wedge} 0,35\right)^{*}\left(1^{\wedge} 0,3\right)^{*}\left(2^{\wedge} 0,2\right)^{*}\left(3^{\wedge} 0,15\right)=2,20$

$S 10=\quad\left(4^{\wedge} 0,35\right)^{*}\left(1^{\wedge} 0,3\right)^{*}\left(1^{\wedge} 0,2\right)^{*}\left(3^{\wedge} 0,15\right)=1,91$

S11 $=\quad\left(4^{\wedge} 0,35\right)^{*}\left(1^{\wedge} 0,3\right)^{*}\left(1^{\wedge} 0,2\right)^{*}\left(3^{\wedge} 0,15\right)=1,91$

$s 12=\quad\left(4^{\wedge} 0,35\right)^{*}\left(2^{\wedge} 0,3\right)^{*}\left(5^{\wedge} 0,2\right)^{*}\left(5^{\wedge} 0,15\right)=3,51$

4. Tahap selanjutnya menghitung nilai vi seperti penjelasan langkah-langkah sebelumnya dimana dari hasil perhitungan vektor $\mathrm{S}$ dari setiap alternatif di bagi dengan jumlah keseluruhannya:

Tabel 1.9 Perhitungan Nilai V 


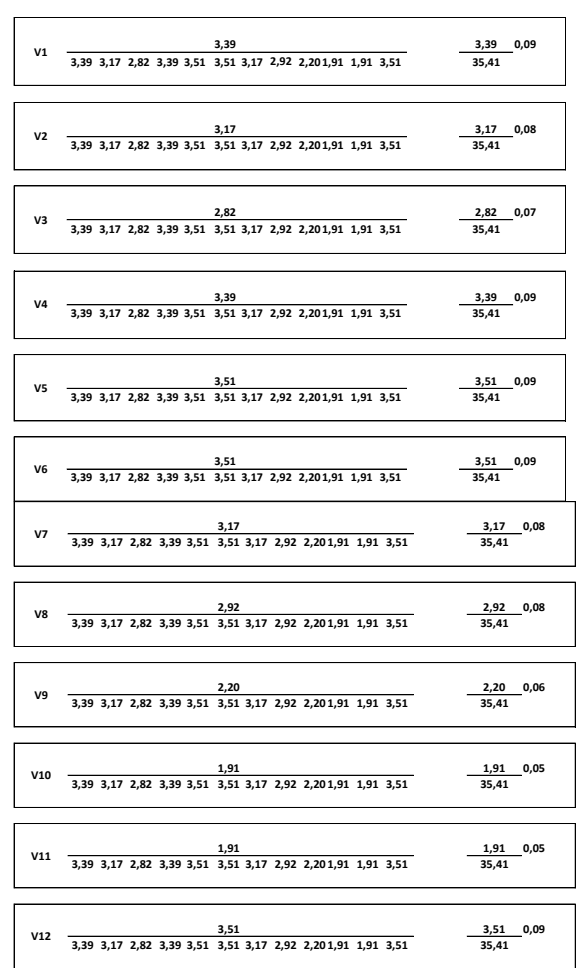

5. Berdasarkan perhitungan di atas maka sistem rekomendasi dosen pembimbing skripsi tersebut di dapatkan Nilai terbaik adalah alternatif yang terpilih dapat dilihat pada Tabel di bawah ini:

\section{Tabel 1.10 Hasil Perangkingan}

\begin{tabular}{|l|l|c|}
\hline NO & \multicolumn{1}{|c|}{ Alternatif } & Nilai \\
\hline 1 & $\begin{array}{l}\text { Untoro } \\
\text { Apsiswanto,S.T., } \\
\text { M.TI }\end{array}$ & 0,09 \\
\hline 2 & $\begin{array}{l}\text { Ridwan Yusuf,S.T., } \\
\text { M.TI }\end{array}$ & 0,09 \\
\hline 3 & $\begin{array}{l}\text { Budi Sutomo, S. } \\
\text { Kom, M.TI }\end{array}$ & 0,09 \\
\hline 4 & $\begin{array}{l}\text { M. Nur Ihksanto, S. } \\
\text { Kom.,M.TI }\end{array}$ & 0,09 \\
\hline 5 & $\begin{array}{l}\text { Heri Nurdianto, } \\
\text { S.Kom.,M.TI }\end{array}$ & 0,09 \\
\hline 6 & $\begin{array}{l}\text { M. Reza Redo } \\
\text { Islami, S.Kom.,M.TI }\end{array}$ & 0,08 \\
\hline 7 & $\begin{array}{l}\text { Tri Aristi Saputri, } \\
\text { S.Kom.,M.TI }\end{array}$ & 0,08 \\
\hline 8 & $\begin{array}{l}\text { M. Adie Syaputra, } \\
\text { S.Kom.,M.TI }\end{array}$ & 0,08 \\
\hline
\end{tabular}

\begin{tabular}{|l|l|c|}
\hline 9 & $\begin{array}{l}\text { Sita Muharni, } \\
\text { S.Kom.,M.TI }\end{array}$ & 0,07 \\
\hline 10 & $\begin{array}{l}\text { Andreas Perdana, } \\
\text { S.Kom.,M.TI }\end{array}$ & 0,06 \\
\hline 11 & $\begin{array}{l}\text { Usep Saparudin, } \\
\text { S.Kom.,M.TI }\end{array}$ & 0,05 \\
\hline 12 & $\begin{array}{l}\text { Sulistiyanto, } \\
\text { S.Kom.,M.TI }\end{array}$ & 0.05 \\
\hline
\end{tabular}

\section{KESIMPULAN DAN SARAN}

\section{a. KESIMPULAN}

1. Terdapat nilai dari hasil perangkingan alternatif tertinggi $\quad 0,9$ dikarenakan Riwayat mengajar paling lama dan terdapat nilai terendah 0,05 dikarenakan dosen tersebut baru mengajar.

2. Metode weighted product dapat digunakan untuk memberikan rekomendasi dosen dikarenakan sudah sesuai dengan proses penentuan dosen pembimbing skripsi yang berjalan saat ini di STMIK Dharma Wacana Metro.

\section{b. SARAN}

1. Disarankan metode ini dapat di implementasikan kedalam sistem rekomendasi pemilihan dosen pembimbing skripsi.

2. Diperlukan adanya pengujian lebih lanjut untuk mengetahui tingkat akurasi dikarenakan belum adanya pengukuran nilai akurat dalam penelitian.

\section{DAFTAR PUSTAKA}

Abdul Jalil, I. P. (2017). SPK PEMBERIAN KREDIT MENGGUNAKAN METODE. Vol.3, No.1, Jan-Jun 2017, 173. 
Arman, T. A. (2019). Sistem Pendukung Keputusan Pemilihan Guru Terbaik. Vol.6 No.2 September 2019, 310.

Fatmi Kasih, Intan Nur Farida. (2017). Sistem Bantu Pemilihan Dosen Pembimbing Tugas Akhir Berdasarkan Kategori Pilihan dan Keahlian Dosen. SNATIKA, 62.

firayati. (2017). SISTEM PENDUKUNG KEPUTUSAN PENENTUAN DOSEN.

Firayati. (2017). Sistem Pendukung Keputusan Penentuan Dosen Pembimbing Tugas Akhir Menggunakan Metode Weighted Product Jurusan Teknik Informatika Fakultas Teknik Universitas Halu Oleo Kendari.

Patmi Kasih. (n.d.). Integrasi Kategori Skripsi Dan Keahlian Dosen Dalam Naïve Bayes Untuk Pemilihan Dosen Pembimbing. Nusantara of Engineering, 10.

Patmi Kasih, Intan Nur Farida. (2017). Sistem Bantu Pemilihan Dosen Pembimbing Tugas Akhir Berdasarkan Kategori Pilihan dan Keahlian Dosen Menggunakan Metode Naive Bayes. SNATIKA, 62.

Rizal Rachman, amirul Mukminin. (2018). Penerapan Metode Certainy Factor Pada Sistem Pakar Penentuan Minat Dan Bakat Siswa SD. IImu Komputer dan informatika.

STMIK, D. W. (2017). Buku Panduan Penulisan Skripsi STMIK Dharma Wacana Revisi III. Metro.

Verdian Putra Wicaksana, Khafiizh Hastuti. (2016). Sistem Rekomendasi Penentuan Dosen Pembimbing Tugas Akhir dengan Menggunakan
Algoritma Rabin-Karp. Teknik Informatika, 6.

Vincentius Riandaru Prasetyo, Budi Hartono, Aldo Adhi Mulyono. (2019). Penentuan Pembimbing Tugas Akhir Mahasiswa Jurusan Teknik Informatika Universitas Surabaya Dengan Metode Dice Coefficient. TEKNIKA, Universitas Surabaya, 8. 